\title{
Editorial for the Inaugural Issue
}

\section{A New Journal For Critical Care Medicine in Sri Lanka}

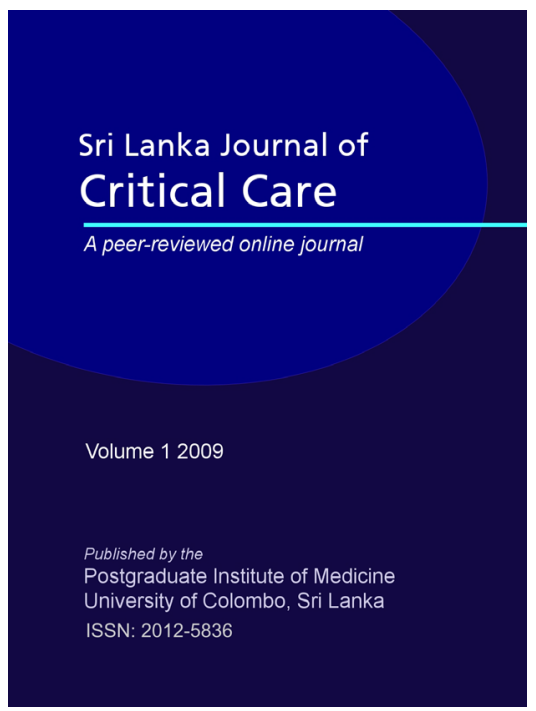

It is with pleasure that we launch the inaugural issue of the Sri Lanka Journal of Critical Care. This is an official publication of the Postgraduate Institute of Medicine, University of Colombo, Sri Lanka.

The journal is peer-reviewed, and is Sri Lanka's first onlineonly open access journal. We do not charge a subscription fee, nor do we charge authors. The open-access model is now a favoured model for publication of scientific research, and enables wider dissemination of scientific publications. Making the journal an online only publication greatly reduces the cost of publication, while making it possible to provide it through an open-access model. The journal aims to foster research and education in critical care medicine in Sri Lanka. We are indexed on Google Scholar.

Critical Care Medicine is gradually being established as a subspecialty in Sri Lanka. The Specialty Board in Critical Care and Emergency Medicine was established by the Postgraduate Institute of Medicine to function under the Board of Study for Multidisciplinary Study Courses recently. As its first activity, a Postgraduate Diploma in Critical Care was commenced this year, and the first batch of trainees have commenced training. The aim of this diploma programme is to enhance the training of junior doctors working in intensive care units throughout the country.

Critical care medicine is essentially a multidisciplinary specialty. In keeping with many models of critical care medicine in Europe, the United States, and other developed countries, we support the view that training in critical care medicine must allow entry from many different disciplines, such as clinical medicine, anaesthesiology, surgery, paediatrics, obstetrics and gynaecology, and many others. We sincerely hope this journal would provide a platform for the dissemination of research, scientific thought and debate in the field of critical care medicine in Sri Lanka. We particular encourage local researchers to submit their work to our journal.

We are grateful for the support given towards us towards the establishment of this journal by the Director, PGIM, the staff at the Medical Education Resource Centre of the PGIM, and members of the Specialty Board in Critical Care, and the Editorial Board. We also thank the INASP (International Network for the Availability of Scientific Publications) which supports us to make our journal available online through their Sri Lanka Journals Online project (www.sljol.info). In particular, we thank Mrs Sioux Cumming, Programme Officer, Publishing Support, INASP, for her continuing support and assistance in maintaining the journal.

\section{Editors:}

Senaka Rajapakse

Head, Department of Clinical Medicine, Faculty of Medicine, University of Colombo, Sri Lanka

Aruna Munasinghe

Consultant Physician, General Hospital Matara, Sri Lanka

Anuja Abayadeera

Senior Lecturer in Anaesthesiology, Faculty of Medicine, University of Colombo, Sri Lanka 